\title{
FACTORS ASSOCIATED WITH NON-SUICIDAL SELF-INJURY IN NON-PSYCHOTIC PATIENTS WITH SUICIDAL IDEATION
}

\author{
Zinchuk M¹, Beghi E², Beghi M³, Bianchi E², Yakovlev $A^{1,4}$, Avedisova $A^{1,5}$, Guekht $A^{1,6}$
}

1 Moscow Research and Clinical Center for Neuropsychiatry, Russian Federation; 2 Department of neurosciences, IRCCS "Mario Negri", Milan, Italy; 3 Department of Mental Health, AUSL Romagna, Ravenna, Italy; 4 Institute of Higher Nervous Activity and Neurophysiology of RAS, Moscow, Russian Federation; 5 Serbsky National Research Centre for Social and Forensic Psychiatry, Russian Federation; 6 Department of Neurology, Neurosurgery and Medical Genetics, Pirogov Russian National Research Medical University, Russian Federation.
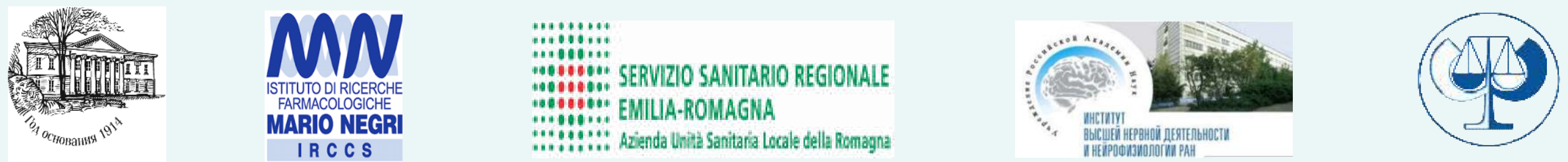

Introduction

Non-suicidal self-injury (NSSI) is recognized as a significant public health concern not only because of increased rates of NSSI over the past decades but also due to the clear association between NSSI and the number of unfavorable outcomes, including suicidal behavior . Little is known about NSSI in Russian Federation, particularly in adult patients with non-psychotic mental disorders (NPMD).

\section{Aim of the study}

Identification of factors related to NSSI among non-psychotic patients with suicidal ideation.

\section{Results}

\section{Methods:}

The study is a retrospective cohort study conducted at the Moscow Research and Clinical Center for Neuropsychiatry between November 2017 and November 2018. The study population was represented by all consecutive patients seen in the center's inpatient psychiatric ward for NPMD. All patients were interviewed using the "Self-Injurious Thought and Behavior Interview» (SITBI) and then underwent a structured interview for the collection of demographic and clinical data. Descriptive statistics, univariate and multivariare analyses were performed.

\section{Inclusion criteria:}

a) permanent residence in Moscow

b) age over 18 years old

c) psychiatric inpatient hospitalization

d) diagnosis of NPMD

e) answering "Yes" to the question "Have you ever had thoughts of killing yourself?" in the Self-injurious thoughts and behavior interview (SITBI)

During the screening 260 patients with suicidal ideation ( $86 \%$ had female sex at birth) were enrolled into the study. Than the sample was divided into 2 groups with and without NSSI. A total of 152 patients (58\%) reported lifetime NSSI. The factors associated with NSSI were age under $35(p<0.0001)$, non-binary gender identity $(p<0.0001)$, incomplete family structure $(p=0.007)$, mental disorder among relatives on mother's side $(p=0.01)$, close relative with NSSI $(p=0.04)$, corporal punishment $(p=0.0004)$, witnessing domestic violence $(p=0.007)$, school bullying $(p<0.0001)$, same-sex sexual experience $(p<0.0001)$ and group sex experience $(p=0.006)$, sexual abuse $(p=0.001)$, body piercing $(p<0.0001)$, tattoos $(p<0.0001)$, scar-covering tattoos $(p=0.003)$, extreme body modification $(p=0.0002)$, age under 30 at first contact with mental health services $(p<0.0001)$, previous drug use experience $(p<0.0001)$, including within past year $(p=0.001)$, comorbid eating disorder $(p<0.0001)$, more than one psychiatric disorder $(p=0.003)$, history of suicidal gestures $(p<0.0001)$ and attempted suicide $(p=0.007)$. Variables found to be significant were included in multivariate analysis models to identify independent predictors of NSSI.

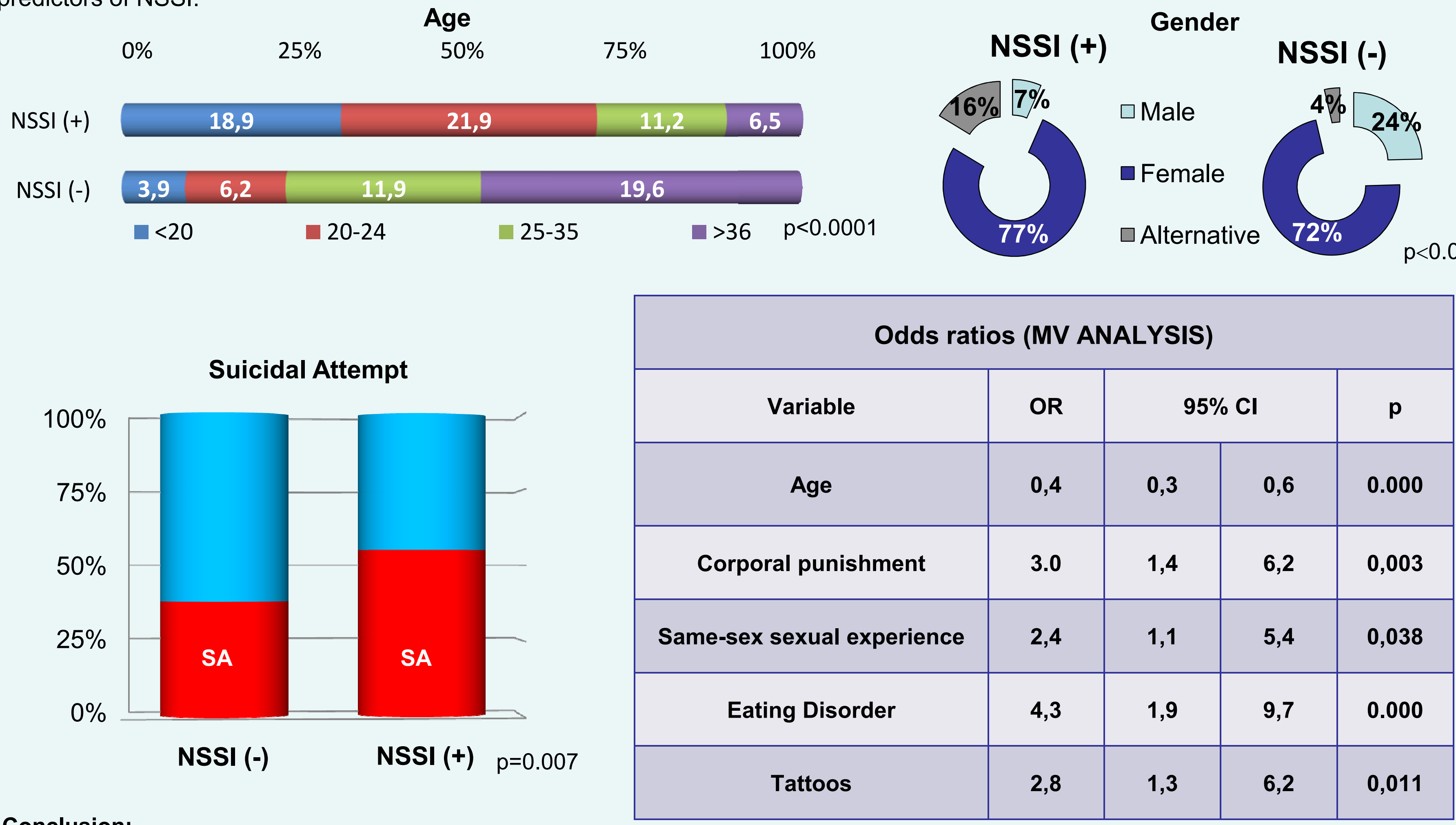

